\title{
Análise da Competitividade de uma Cooperativa Agroindustrial do Oeste Catarinense
}

\author{
Josiane Weber ${ }^{1}$ \\ Andressa Morgan ${ }^{2}$ \\ César Augustus Winck ${ }^{3}$
}

\section{RESUMO}

Este artigo buscou analisar as vantagens competitivas de uma empresa cooperativa agroindustrial de grande porte localizada no oeste catarinense a luz da cadeia de valor. Foi realizado um diagnóstico dos dados econômicos da empresa através de seus relatórios de gestão a fim de verificar seu crescimento econômico, assim como relacionar seu crescimento com a teoria e em relação ao mercado. O estudo consiste em uma pesquisa descritiva, cuja abordagem se classifica em qualitativa, a coleta de dados considerou os dados secundários disponibilizados através de demonstrativos financeiros. Desta forma, foi possível constatar o crescimento e desempenho financeiro vertical da cooperativa, bem como sua importância socioeconômica. Portanto, conclui-se que a tendência da empresa estudada esta voltada à consolidação no mercado bem como prospecção de crescimento.

Palavras-chave: Cooperativismo. Competitividade. Crescimento econômico.

\section{Analysis of the competitiveness of an agroindustrial cooperative from Santa Catarina state, brazil}

\begin{abstract}
This article sought to analyze the competitive advantages of a large agroindustrial cooperative located in Western Santa Catarina in the light of the value chain. A diagnosis of the company's economic data was made through its management reports in order to verify its economic growth, as well as to relate its growth with theory and in relation to the market. The study consists of a descriptive research, whose approach is classified as qualitative; the data collection considered the secondary data provided by financial statements. Thereby, it was possible to verify the cooperative's vertical financial growth and performance, as well as its socioeconomic importance. Therefore, it is concluded that the studied company's tendency is focused on its consolidation on the market and on forward growth as well.
\end{abstract}

Keywords: Cooperatives. Competitiveness. Economic growth.

\section{INTRODUÇÃO}

Empresas cooperativas são fundamentadas conforme os princípios da doutrina da Sociedade dos Probos de Rochdale que "[...] criou os princípios morais e a conduta que são

\footnotetext{
${ }^{1}$ Mestranda em Administração pela UNOESC. E-mail: josiweber@yahoo.com.br

2 Mestra em Administração pela UNOESC. E-mail: dressamorgan@ hotmail.com

3 Doutor em Agronegócios (UFRGS). Mestre em Ciências Veterinárias. Médico Veterinário e Administrador. Docente permanente do Mestrado Profissional em Administração da UNOESC. cesar.winck@ unoesc.edu.br
} 
considerados, até hoje, a base do cooperativismo autêntico" (OCESP, 2014), seguindo suas normas organizacionais. Desta forma, o cooperativismo é constituído através de iniciativas econômicas e a composição de uma sociedade (GALERIANI, 2003).

As cooperativas agropecuárias desenvolvem importante papel de cunho econômico e social no desenvolvimento local e regional. Representam uma das poucas possibilidades de pequenos e médios agricultores inserirem se em mercados concentrados, ainda corrobora com o valor agregado do produto (FERREIRA; BRAGA, 2004).

Assim como as demais organizações as empresas cooperativas estão propensas às dificuldades de sobrevivência no mercado. Este vetor pode ser relacionado ao crescimento econômico mundial acelerado e mais competitivo, o que coloca as organizações melhor constituídas à frente de seus concorrentes, estabelecendo sua consolidação no mundo dos negócios.

Em relação aos fatores determinantes para que empresas possam criar ou sustentar vantagens competitivas está à concorrência, ou seja, o sucesso ou fracasso da empresa está voltado ao seu ambiente. Para tanto, entender a estratégia competitiva proposta por Porter (1989) é necessário analisar a atratividade comercial em termos de rentabilidade em longo prazo e os fatores que a definem. A partir do momento em que a indústria passar a verificar a concorrência de modo em que encontre as regras que determinem sua atratividade será possível identificar o conjunto de forças competitivas que resultem em sua viabilidade econômica.

Considerando as cooperativas agropecuárias pelo viés econômico o estudo tem como principal objetivo analisar suas vantagens competitivas baseando se na teoria da cadeia de valor, bem como relacionar seu crescimento econômico com esta teoria, analisar a competitividade da cooperativa em relação ao mercado e realizar uma análise dos relatórios de gestão a fim de verificar seu desempenho econômico. Pretende-se com o estudo responder quais as vantagens competitivas de uma empresa cooperativa podem ser relacionados à teoria do modelo do Diamante de Porter.

O estudo desenvolvido justifica se pela importância das cooperativas como vetor de desenvolvimento junto à sociedade, não somente ao produtor, mas sim a família e o adensamento econômico gerado partindo do nível local para o global. Contundo demonstrar através das prospecções de resultados econômicos o crescimento destas organizações através de ações voltadas às pessoas que trabalham em conjunto, com o mesmo objetivo. 
O estudo contribui ainda de maneira a apresentar academicamente o espaço cooperativista pelo viés socioeconômico, já que há poucos estudos realizados neste âmbito e que proporcionam análises embasadas na teoria da cadeia de valores.

O presente trabalho foi organizado da seguinte forma, além desta introdução: (i) referencial teórico, onde buscou se apresentar e relacionar ideias e construtos teóricos da teoria do modelo do diamante de Porter e sua aplicação em empresas cooperativas; (ii) apresenta a metodologia aplicada ao caso de pesquisa; (iii) apresenta e analisa e interpretação de dados; (iv) discussão dos resultados e; (v) as considerações finais da pesquisa.

\section{O COOPERATIVISMO E A COMPETITIVIDADE NO CENÁRIO ATUAL DO MERCADO}

As transformações ocorridas nas transações do ambiente de negócios nos últimos anos motivaram uma maior competição entre as empresas assim como maior instabilidade econômica nos setores comerciais (SUSZEK, 2012).

Para Paraginski (2014) o processo acelerado de mudanças no mercado global entre empresas do setor do agronegócio acelera a competitividade entre elas. Desta forma, o crescente aumento de informações desencadeia o aumento de novos produtos disponibilizados ao consumidor e as formas facilitadas de aquisição estimulam as empresas do setor a competir mais.

Empresas cooperativas agroindustriais desenvolvem papel essencial na economia e na sociedade. Para tanto precisam estar solidificadas no processo de formação e estruturação, e possuírem estratégias voltadas a atender as necessidades do segmento cooperativista, seja no mercado competitivo ou relacionados aos produtores rurais e sua participação no setor agrícola (GALERIANI, 2003).

Neste cenário de competição empresarial a sobrevivência econômica da organização consiste em elos formados e direcionadas a um mesmo objetivo. (Galeriani, 2003). Empresas cooperativas ou não precisam estabelecer estratégias competitivas voltadas ao desempenho econômico de seus negócios (GIMENES; GIMENES, 2007).

Desse modo, Suszek (2012) posiciona as cooperativas entre as economias particulares de seus associados e mercado. Desta forma, desempenham relação de intermediários entre os mercados e os associados, a fim de promover maiores recursos financeiros para ambas as economias. Neste sentido, a competitividade destas organizações torna-se crucial em relação 
às perspectivas de crescimento, pois são responsáveis pelo desenvolvimento socioeconômico e a continuidade da empresa e seus associados.

Cooperativas agroindustriais são definidas como formas de integração vertical dos produtores agropecuários integrando as atividades de comercialização, industrialização e produção de insumos (ZYLBERSTAJN, 1994).

O enfoque das cooperativas agroindustriais está na contribuição para a promoção do crescimento econômico local através da geração de renda e inclusão social no meio rural, desempenhando prestação de serviços e acesso a tecnologia aos produtores garantindo a atuação eficiente na cadeia. Desta forma, exerce papel fundamental na comercialização e agregação de valores a produção agrícola de pequenos agricultores do país (SUSZEK, 2012). Gimenes; Gimenes (2007) complementam que empresas cooperativas direcionam poder de barganha a estes produtores em mercados relativamente imperfeitos e contribuem para uma melhor qualidade de vida através da distribuição equitativa de recursos.

Para Galeriani (2003), ainda a baixos índices de trabalhos acadêmicos neste seguimento, dada relevância das empresas cooperativas na economia do país. Relacionada como seu desempenho de crescimento, a intensificação contínua de seus negócios que estabelecem maior competitividade no panorama atual do mercado. Neste sentido, situa a necessidade de alianças com outras empresas a fim de fortalecer os vínculos empresariais garantindo retornos financeiros e a sobrevivência do cooperativismo em curto e longo prazo.

No Brasil as cooperativas possuem legislação especifica diferente das demais empresas, seguem as diretrizes da Lei 5.764 de 16 de dezembro de 1971 '“...] que as define como um contrato celebrado entre pessoas que reciprocamente contribuem com bens ou serviços para o exercício de uma atividade econômica, de proveito comum, sem objetivar o lucro" (OCESP, 2014).

Mudanças ocorridas nos anos 80 e 90 no cenário cooperativo brasileiro envolvendo os setores políticos e econômicos obrigaram estes modelos de empresa a se adaptarem ao mercado. Durante esta transição algumas cooperativas estacionaram ou perderam sua participação no mercado. Outras, porém, buscaram inovações para modernizar seus recursos, aumentado consequentemente sua competitividade frente ao ambiente de negócios mantendo a identidade cooperativa (FERREIRA; BRAGA, 2004).

Outra consideração importante ao desenvolvimento deste estudo na concepção destes autores está voltada a utilização de estratégias competitivas pelas cooperativas agroindustriais. 
Dado o fato de sua implementação possibilitar distinguir se no ambiente de incertezas e sobressaírem frente à concorrência.

Pode se considerar como vantagens competitivas das cooperativas as incorporações das inovações e diversificações de produtos para ajustar se as demandas de mercado (FERREIRA; BRAGA, 2004).

\subsection{DIAMANTE DE PORTER}

Porter (2009) relaciona a competitividade nacional à produtividade, que por sua vez esta ligada á inovação. Segundo o autor, as pressões e desafios possibilitam as empresas obterem vantagem competitiva internacionalmente.

O Modelo Diamante (Figura 01) foi proposto por Porter em 1990, tem por objetivo explicar a competitividade de determinados setores da economia de um país em relação a outros países. Identifica alguns fatores que influenciam na competitividade das nações em uma determinada indústria.

O modelo agrupa em quarto os atributos determinantes da vantagem competitiva nacional: condições dos fatores (mão-de-obra qualificada, conhecimentos técnicos e científicos e infraestrutura); estratégia, estrutura e rivalidade (as condições no país que determinam como as empresas são constituídas, organizadas e gerenciadas, e ainda a rivalidade no mercado interno); condições da demanda (natureza da demanda no mercado interno para os produtos ou serviços da indústria); e setores correlatos e de apoio (a presença ou ausência, no país, de industriais fornecedoras competitivas internacionalmente) (PORTER, 2009).

O Modelo Diamante de Porter segundo Silva, Silva e Motta (2012) foi obtido através de uma pesquisa qualitativa e é utilizado como uma base para construção dos indicadores de competitividade.

Figura 1: Determinantes da vantagem nacional

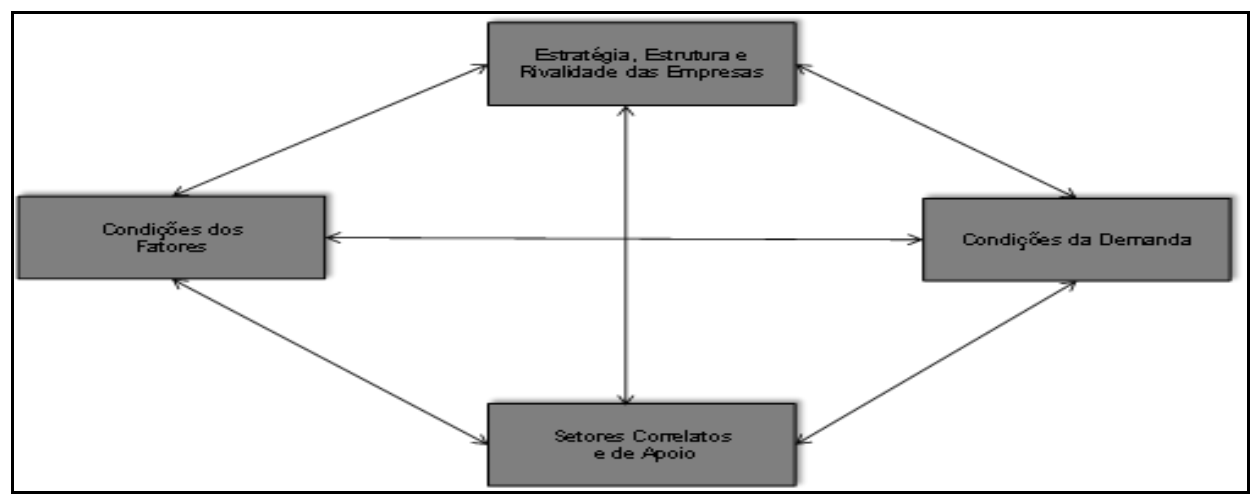

Fonte: Porter, (2009, p. 182) 
As características de cada um dos atributos que compõe o Diamante de Porter são explicitadas a seguir.

\subsubsection{Condições de Fatores}

Engloba aspecto referente aos fatores de produção, são elencados cinco tipos de recursos: recursos humanos, recursos físicos, recursos de conhecimento, recursos de capital e infraestrutura (PORTER, 2009).

Quanto aos recursos humanos deve ser observada a existência de mão de obra especializada, ética profissional e custos envolvidos. Os recursos físicos envolvem a localização geográfica, fatores climáticos, disponibilidade dos recursos naturais, entre outros. Os recursos de conhecimento abrangem o conhecimento técnico e científico do país. O mercado de capitais e os recursos financeiros são exemplos de recursos de capital. A infraestrutura abrange questões relacionadas à logística e transportes (PORTER, 2009).

\subsubsection{Condições de demanda}

Possuem relação com a natureza da demanda interna dos produtos e serviços oferecidos. Segundo Natário Neto (2006) auxiliam as empresas na identificação prévia das necessidades dos consumidores. Caso os consumidores internos sejam exigentes e requeiram produtos sofisticados podem contribuir para antecipação da demanda externa fomentando as inovações e garantindo vantagem competitiva para as empresas.

A demanda interna de um país é o fator que determina a busca por inovação. As características a serem consideradas com relação à demanda são as seguintes: a composição, relacionada às necessidades dos consumidores e a maneira como as empresas atendem e antecipam estas necessidades; o tamanho e a exportação de valores e da preferência interna, assim como seus produtos (PORTER, 2009).

\subsubsection{Setores correlatos e de apoio}

Refere-se a indústrias que possuem atividades ligadas à atividade da empresa, salienta se a necessidade de estas indústrias correlatas apresentarem se competitivas internacionalmente para obtenção de resultados satisfatórios. 
A vantagem competitiva se dá pelo intercâmbio de tecnologias e pelo incentivo ao desenvolvimento de indústrias fornecedoras.

Os fornecedores e usuários finais que se localizam próximos uns dos outros auferem as vantagens das linhas de comunicação mais curtas, do fluxo de informações rápido e contínuo e do intercâmbio constante de ideias e de inovações. As empresas têm a oportunidade de influenciar o esforço técnico dos fornecedores e são capazes de servir como campo de teste para os trabalhos de $\mathrm{P} \& \mathrm{D}$, acelerando o ritmo da inovação. (PORTER,2009, p. 191)

\subsubsection{Estratégia, estrutura e rivalidade das empresas}

Este atributo pode ser visualizado através das condições de criação, organização e gestão das empresas dentro do país, considerando as condições em que se determina a rivalidade interna. O ponto mais importante do Diamante é a rivalidade interna, "em razão do vigoroso efeito estimulante sobre os demais" (PORTER, 2009, p.195). O autor salienta que a rivalidade interna pode preparar as empresas para competir em mercados internacionais.

A vantagem competitiva nacional pode ser vista como resultado do equilíbrio entre a organização, as estratégias e as metas das indústrias e ainda por sua escolha pela competição, estes aspectos variam em função do contexto de cada país (NATÁRIO NETO, 2006).

\subsubsection{Outros Aspectos Relevantes}

- O acaso: são acontecimentos que divergem dos cenários previstos previamente, surgindo de surpresa. (NATÁRIO NETO, 2006). Segundo Porter (2009) o acaso está relacionado a fatos que fogem do alcance das empresas, como guerras, decisões de governos internacionais, entre outros fatores que interferem na competitividade, caso não ocorra interferência o acaso pode ser desconsiderado.

- O governo: cada um dos atributos do modelo representa um ponto do diamante, que pode ser influenciado de maneira positiva ou negativa pela atuação do governo, o qual também pode ter sua política governamental influenciada por estes atributos. O apoio do governo para desenvolvimento das indústrias se dá através de políticas sociais e econômicas, de subsídios, políticas financeiras, investimento em educação entre outras ações. (PORTER, 2009). 
Uma confirmação empírica do modelo Diamante de Porter (2009) se deu através do estudo realizado por Silva, Silva e Motta (2012), que teve a amostra composta por 49 países, representando $74,2 \%$ da população mundial e 93,4\% do PIB mundial nominal, valores referentes ao ano de 2007. Os resultados deste trabalho apontaram uma relação entre os indicadores de competitividade do país e o desempenho sustentável de suas empresas.

\section{METODOLOGIA}

O presente estudo buscou analisar os dados dos relatórios de gestão da Cooperativa "A", referentes aos anos de 2012 e 2013. Para atingir os objetivos propostos, foi desenvolvido um estudo descritivo, tendo em vista que busca descrever um fenômeno. De acordo com Collis e Hussey (2005), o estudo descritivo visa à identificação, avaliação e descrição de um problema.

A abordagem da pesquisa foi qualitativa, que consiste em entender os significados atribuídos pelos indivíduos a determinado problema humano ou social. (CRESWELL, 2010). Segundo Godoy (1995) os fenômenos são mais bem compreendidos em seu contexto.

A pesquisa documental foi utilizada para a coleta dos dados, as informações foram obtidas através dos relatórios de gestão disponibilizados no site da Instituição. De acordo com Godoy (1995) este tipo de pesquisa envolve uma pré-análise, através da qual se dá a seleção, organização e leitura "flutuante" do material. Compreende também uma segunda fase, que visa à exploração dos documentos através de uma leitura mais aprofundada, codificação, classificação e categorização do material. Segundo Yin (2010) uma das vantagens da pesquisa documental é o fato de os documentos serem estáveis, exatos e de ampla cobertura.

As categorias de análise foram definidas através dos preceitos do Diamante de Porter, os atributos determinantes da vantagem competitiva nacional: condições dos fatores, condições da demanda, setores correlatos e de apoio e estratégia, estrutura e rivalidade das empresas. A próxima seção traz a apresentação dos dados, sua análise e discussão.

\section{APRESENTAÇÃO E ANÁLISE DOS DADOS}

O presente estudo foi desenvolvido através da análise e diagnóstico de informações disponíveis em meio eletrônico da empresa Cooperativa “A”, fundada na década de 60, 
seguindo a doutrina cooperativista nacional. Em constante ascensão no mercado está presente em mais de setenta municípios catarinenses. (DADOS DA PESQUISA, 2014).

A seguir apresenta se o quadro da estrutura organizacional da empresa.

Tabela 01: Estrutura organizacional

\begin{tabular}{|l|c|}
\hline \multicolumn{1}{|c|}{ ESTRUTURA } & NO DE UNIDADES \\
\hline AGROPECUÁRIAS & 76 \\
\hline MERCADOS & 57 \\
\hline SILOS GRANELEIROS & 35 \\
\hline UNIDADES DE RECEBIMENTO DE GRÃOS & 6 \\
\hline UNIDADE DE BENEFICIAMENTO DE SEMENTE & 3 \\
\hline INDÚSTRIAS: TRIGO, SOJA E MILHO & 3 \\
\hline RESFRIAMENTO DE LEITE & 2 \\
\hline UNIDADE PRODUTORA DE LEITÕES & 2 \\
\hline FÁBRICAS DE RAÇÃO & 2 \\
\hline POSTOS DE COMBUSTÍVEIS & 2 \\
\hline CENTRO DE DISTRIBUIÇÃO & 2 \\
\hline INDÚSTRIA DE SOJA DESATIVADA & $\mathbf{1}$ \\
\hline
\end{tabular}

Fonte: Dados da Pesquisa (2014).

Dando sequência a pesquisa são apresentados os dados de acordo com seus respectivos objetivos específicos, bem como a análise dos mesmos em relação à teoria referida.

O primeiro objetivo específico consiste em fazer um diagnóstico da diversificação produtiva da empresa cooperativa para analisar sua participação no mercado considerando estes aspectos como vantagens competitivas ou não. Sendo que o diagnóstico foi realizado a partir da análise das atividades desenvolvidas pela Cooperativa "A", disponibilizadas em documentos eletrônicos.

A principal atividade da Cooperativa "A" é a comercialização e armazenagem das produções agrícolas desenvolvidas por seus associados, sendo: milho, soja, feijão e trigo. Contando com a industrialização do trigo e soja, a fabricação de ração, ainda atua no beneficiamento de sementes certificadas de soja, feijão, trigo e coberturas de solo. Outro fator de diversificação produtiva está em parcerias industriais com empresas do sistema cooperativo as "coirmãs" no beneficiamento de citros, suínos, aves e leite. Além disso, conta com revenda de combustíveis e lubrificantes. (DADOS DA PESQUISA, 2014).

Com estes dados foi possível verificar a diversidade de produtos disponibilizados ao mercado a fim de constatar sua atratividade empresarial frente aos concorrentes. 
Outro dado do estudo foi a identificação dos benefícios cooperativos aos produtores rurais. Foi correlacionado em relação a estes benefícios ao sistema cooperativista, como o aperfeiçoamento contínuo de novas técnicas e tecnologia. Bem como apurar as condições sanitárias em geral, continua assistência técnica, desenvolver recursos para aumentar a produtividade e expectativa de vida. Ainda disponibiliza o fornecimento de insumos, como sementes, fertilizantes, corretivos e medicamentos veterinários. Tendo como objetivo central a agregação de valor a produção agrícola retornada ao beneficio de seus cooperados. "Visando elevar a qualidade de vida das famílias rurais, melhorar o trabalho e a produção [...]" (DADOS DA PESQUISA, 2014).

Desta forma, é possível responder a outro objetivo da pesquisa que está em relacionar o sistema cooperativo com o Modelo do Diamante de Porter. Sendo possível correlacionar os fatores dos determinantes da vantagem competitiva com base nos estudos desenvolvidos.

Iniciando com a condição dos fatores na Cooperativa "A" pode se levantar os recursos humanos, físicos, de conhecimento, de capital e infraestrutura bem identificados e fortalecidos dentro da organização. Sendo que os investimentos imobilizados somaram no último ano aplicações de $104,02 \%$ um aumento de $54,85 \%$ em relação a 2012. O quadro de associados somou um aumento de $3,17 \%$ e pretende chegar ao mínimo a 16.500 famílias ao final de 2014. Já o número de colaboradores para atender a demanda cresce de acordo com os investimentos concluídos, em 2013 foram contratados 275 funcionários, conforme gráfico abaixo:

Gráfico 01: Colaboradores

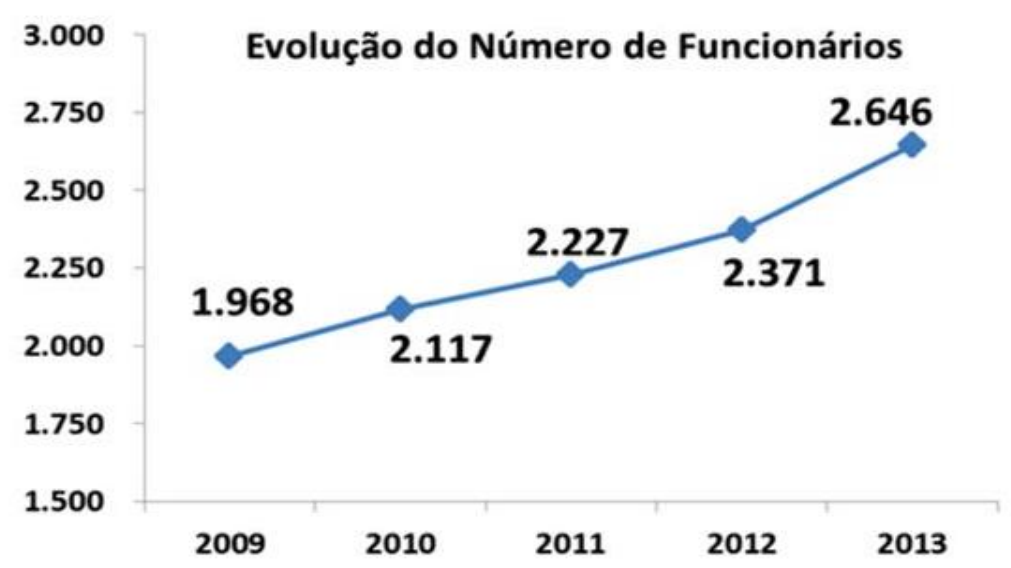

Fonte: Dados da Pesquisa (2014).

No enfoque das condições de demanda a cooperativa estudada busca atender as exigências de mercado, que pressionam a inovar e diversificar cada vez mais o leque de 
opções, conforme foi constatado nas respostas do primeiro objetivo apresentado. Ainda buscando antecipar as tendências do mercado externo, gerando a vantagem competitiva.

No que tange as indústrias correlatas e de apoio, o terceiro determinante do diamante de Porter está voltada às parcerias com outras indústrias do setor cooperativo no beneficiamento de outros produtos a fim de aumentar a competitividade do mercado para ambas às organizações.

Para complementar o determinante do diamante está o atributo estratégias, estrutura e rivalidade entre as empresas sendo considerado o propulsor do ambiente competitivo. Assim as estratégias e praticas administrativa desempenham posição de destaque no mercado. Fato analisado na industrialização de produtos, na comercialização de suprimentos que possibilita a inovação superior aos seus competidores. Gerado através da diversificação de recursos dentro da cooperativa.

Com base nos dados secundários pesquisados nos relatórios de gestão da empresa nos últimos anos foi possível observar o crescimento econômico da cooperativa agroindustrial em questão e responder ao último objetivo da pesquisa.

Gráfico 02: Análise do crescimento econômico

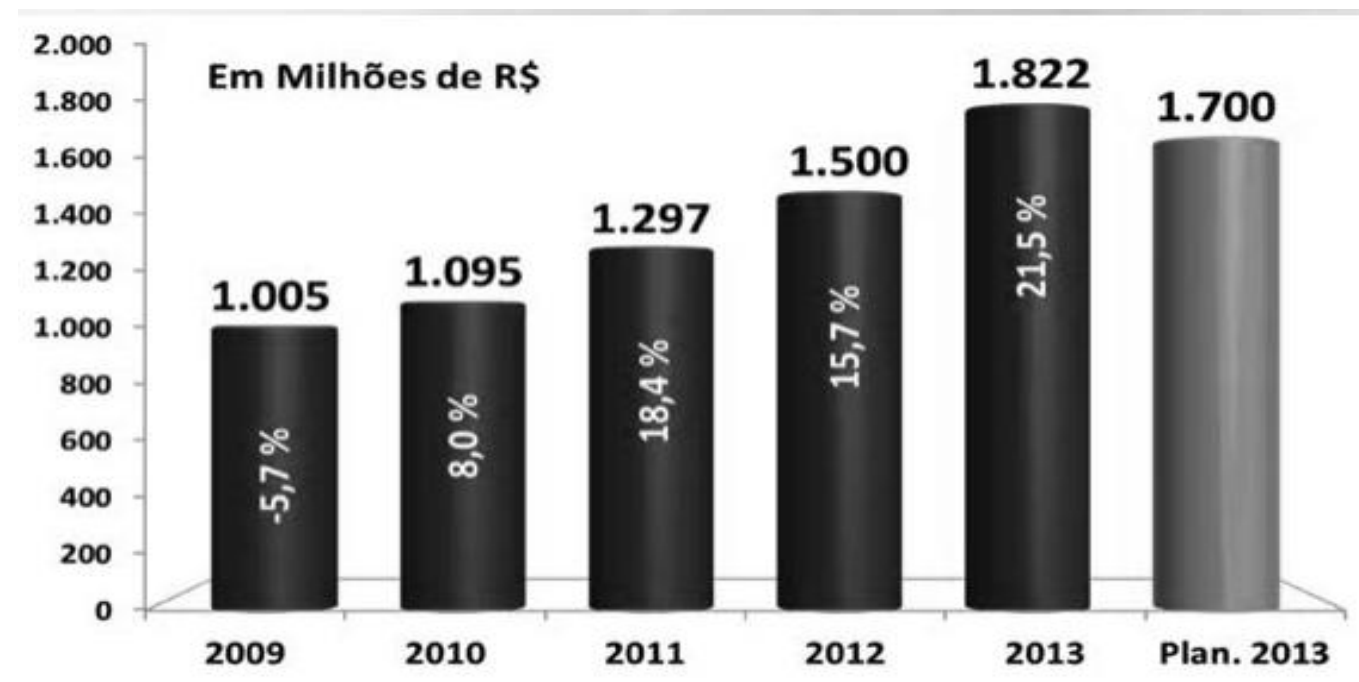

Fonte: Dados da Pesquisa (2014).

$\mathrm{Na}$ análise destes dados é possível constatar o crescimento vertical da empresa. Sendo que a estimativa de crescimento para o último ano era de $15 \%$ superou o esperando chegando a 21,5\%. (DADOS DA PESQUISA, 2014). 
Quadro 01: Analise dos resultados

\begin{tabular}{|l|l|}
\hline \multicolumn{1}{|c|}{ Objetivos Específicos } & \multicolumn{1}{|c|}{$\begin{array}{c}\text { Resposta Obtida na Análise dos } \\
\text { Documentos Eletrônicos }\end{array}$} \\
\hline $\begin{array}{l}\text { Fazer um diagnóstico da diversificação } \\
\text { produtiva da cooperativa para analisar } \\
\text { sua competitividade no mercado; }\end{array}$ & $\begin{array}{l}\text { Número de atividades produtivas desenvolvidas pela } \\
\text { cooperativa; }\end{array}$ \\
\hline $\begin{array}{l}\text { Identificar os benefícios da cooperativa } \\
\text { ao produtor rural; }\end{array}$ & $\begin{array}{l}\text { Melhorar a qualidade de vida dos produtores rurais, } \\
\text { disponibilizadas de varias formas; }\end{array}$ \\
\hline $\begin{array}{l}\text { Relacionar o sistema cooperativo } \\
\text { agroindustrial com a teoria do } \\
\text { Diamante de Porter }\end{array}$ & $\begin{array}{l}\text { Fatores do Modelo do Diamante de Porter identificados no } \\
\text { sistema cooperativo; }\end{array}$ \\
\hline $\begin{array}{l}\text { Analisar o crescimento econômico da } \\
\text { cooperativa em relação ao mercado; }\end{array}$ & $\begin{array}{l}\text { Desempenho econômico verificado através do gráfico de } \\
\text { crescimento. }\end{array}$ \\
\hline
\end{tabular}

Fonte: Os autores.

Com a coleta de dados efetuada, foi possível responder as questões da pesquisa através da conexão da teoria com as fontes levantadas durante o processo de diagnóstico. Neste sentido, consta se a perspectiva de crescimento do sistema cooperativo estabelecido pelas tendências de mercado e atratividade destas organizações.

\subsection{DISCUSSÃO DOS RESULTADOS}

Para Porter (1989) a competitividade das organizações esta voltada à capacidade de atratividade da indústria. Desse modo, a diversificação de produtos operacionalizada pela cooperativa atende a demanda do mercado, porém paralelos a este fator está à inovação de recursos que por sua vez desencadeiam a vantagem competitiva. Já Suszek (2012) estabelece que a pressão pela competição desempenha papel propulsor da indústria frente à inovação, sendo que os investimentos devem estar focados a este segmento.

De acordo com Ferreira e Braga (2004) um dos fatores propulsores da diversificação das atividades cooperativas está relacionado ao baixo retorno econômico da principal atividade da indústria. Outro aspecto considerado pelos autores como fator de diversificação está nas sobras do processo produtivo. Visando minimizar os riscos de comercialização e impulsionar às receitas a diversificação torna se uma vantagem competitiva.

Cabe destacar a importância dos recursos humanos da cooperativa com o número crescente de associados e colaboradores. O que contribui aos fatores de desempenho serem criados de acordo com as necessidades de demanda existentes e ainda impulsionarem o crescimento financeiro originando o desenvolvimento de fatores produtivos individualizados e continuo aprimoramento. 
Segundo Paraginski (2014), a geração de valor nos processos industriais está relacionada com as inovações em seu nível organizacional, para que desta forma possam somar seu grau de competitividade e permanecer no mercado.

A centralização das empresas de setores correlatos e de apoio em uma mesma região pode ser entendida como um benefício empresarial (SUSZEK, 2012). Desta forma a Cooperativa "A" desencadeou parcerias importantes na agregação de valor de seus produtos. Fato este estabelecido com empresas do mesmo setor, que permitiram destacar se em mercados segmentados e exigentes. Ou seja, a competitividade no ambiente de negócios torna se mais efetiva a partir da junção das forças desencadeadas entre elas. Ainda nesse sentido, pode se analisar a redução de custos operacionais no beneficiamento na produção.

Para complementar a importância destas alianças estratégicas cooperativas está à redução de custos operacionais com o aumento da produção de escala, reduzindo ainda custos administrativos e financeiros. Outra vantagem competitiva deste elo está na agilidade das decisões empresariais, com a parcela igualitária dos custos tecnológicos (GALERIANI, 2003).

Ainda Galeriani (2003) propõe a aliança estratégica como uma oportunidade de intensificar seus negócios e sobreviver no mercado cada vez mais competitivo. Podendo ser avaliada entre os cooperativistas como benéfica ou não, cabendo desta forma a avaliação comparativa dos custos.

Baseado nos estudos de Ferreira e Braga (2004) os melhores resultados de desempenho das cooperativas agropecuárias estão correlacionados a quantidade de produção diversificada efetivada por uso de recursos desta abordagem. Outro fator de relevância está relacionado a maior abrangência de mercado formalizada pelas cooperativas. Neste aspecto, ocorre a inserção das cooperativas em outros setores comerciais ligados a diversificação de produção. Assim as cooperativas diversificadas desempenham "[...] o maior aproveitamento de recursos disponíveis e oportunidades, por meio de uma atitude empreendedora" (FERREIRA; BRAGA, p. 51, 2004).

\section{CONSIDERAÇÕES FINAIS}

Propondo-se a analisar as vantagens competitivas de uma empresa cooperativa à luz do modelo do Diamante de Porter, verifica se que o principal objetivo foi alcançado. Já que foi 
possível observar as vantagens competitivas da cooperativa, através das diversidades e inovação de produtos, relacionando com teoria.

Constatou-se com o estudo que a uma tendência na consolidação da cooperativa no mercado. Fato este estabelecido pelas parcerias realizadas por indústrias do mesmo sistema produtivo. $\mathrm{O}$ que possibilita analisarmos o crescimento vertical das empresas cooperativas ao compararmos com as instabilidades do ambiente do negócio.

Como contribuição, acredita-se que a pesquisa desenvolvida tem bases sólidas, no sentido de fornecer um diagnóstico do processo do modelo do Diamante de Porter, bem como instigar e estimular a ampliação e melhoria. Academicamente, compreende se que o estudo possibilita o aprofundamento teórico de uma prática organizacional, embasada em uma teoria e, portanto, com subsídios referenciados.

\section{REFERÊNCIAS}

COLLIS, Jill; HUSSEY, Roger. Pesquisa em administração: um guia prático para alunos de graduação e pós-graduação. 2. ed. Porto Alegre: Bookman, 2005.

CRESWELL, John W. Projeto de pesquisa: métodos qualitativos, quantitativos e misto. 3. ed. Porto Alegre: Artmed, 2010.

FERREIRA, Marco Aurélio Marques; BRAGA, Marcelo José. Diversificação e competitividade nas cooperativas agropecuárias. RAC, v. 8, n. 4, out./dez. 2004

GALERANI, Jair. Gestão de operações e logística: formação, estruturação e implementação de aliança estratégica entre empresas cooperativas. RAE - eletrônica - vol. $2 \cdot \mathrm{n}^{\mathrm{o}} 1$. jan./jun.2003.

GIMENES, Régio Marcio Toesca; GIMENES, Fátima Maria Pegorini. Agronegócio cooperativo: a transição e os desafios da competitividade. REDES, Santa Cruz do Sul, v. 12, n. 2, p. 92-108 mai./ago. 2007.

GODOY, Arilda Schmidt. Pesquisa qualitativa: tipos fundamentais. Revista Administração de Empresas. São Paulo, v.35, n.3, Jun. 1995. Disponível em: 〈http://www.scielo.br/scielo. php?script=sci_arttext\&pid=S0034-75901995000300004\&lng=en\&nrm=iso >. Acesso em: 12 jun. 2014.

NATÁRIO NETO, J. R. O diamante de Porter em estudo exploratório multicaso no setor pesqueiro exportador de Santos. 2006. (Dissertação Mestrado em Gestão de Negócios) Universidade Católica de Santos, Santos, 2006. Disponível em: 〈http://www.novomilenio.inf.br/baixada/bs004c6.htm>. Acesso em: 10 jun. 2014.

OCESP. O que vem a ser uma sociedade cooperativa? Disponível em: http://www.ocesp.org.br/default.php?p=texto.php\&c=0_que_vem_a_ser_uma_sociedade_coo 
perativa. Acesso em: 11 jul. 2014.

PORTER; Michael Eugene. Vantagem competitiva: criando e sustentando desempenho superior. 13 ed., Rio de Janeiro: Campus, 1989.

PORTER. Competição: estratégias competitivas essenciais. 4. ed., Rio de Janeiro: Campus, 1999.

SILVA, Martim Francisco de Oliveira e; SILVA, Jorge Ferreira da; MOTTA, Luiz Felipe Jacques da. A vantagem competitiva das nações e a vantagem competitiva das empresas: o que importa na localização? RAP. v. 46, n. 3, p. 701 - 720, 2012.

SUSZEK, Ana Claudia. Análise da vantagem competitiva das cooperativas agroindustriais do oeste do Paraná, baseada no diamante de Porter. Rev. Ciênc. Empresas. UNIPAR, Umuarama, v. 13, n. 1, p. 139-156, jan./jun. 2012.

YIN, Robert K. Estudo de Caso: planejamento e métodos. 4 ed. Porto Alegre: Bookman, 2010.

ZYLBERSZTAJN, Decio. Organização de cooperativas: desafios e tendências. Revista de Administração, São Paulo v.29, n.3, p. 23-32, julho/setembro 1994. 